OPEN ACCESS

Edited by:

Kathryn M. Lenz,

The Ohio State University,

United States

Reviewed by:

Urte Neniskyte,

Vilnius University, Lithuania

Maurizio Giustetto,

University of Turin, Italy

Caroline Smith,

Duke University, United States

*Correspondence:

Agnès Nadjar

agnes.nadjar@u-bordeaux.fr

tThese authors share senior authorship

Specialty section: This article was submitted to

Non-Neuronal Cells,

a section of the journal

Frontiers in Cellular Neuroscience

Received: 26 October 2021

Accepted: 17 January 2022

Published: 10 February 2022

Citation:

Decoeur F, Picard K,

St-Pierre M-K, Greenhalgh $A D$,

Delpech J-C, Sere A, Layé S,

Tremblay M-E and Nadjar A (2022)

N-3 PUFA Deficiency Affects

the Ultrastructural Organization and Density of White Matter Microglia in the Developing Brain of Male Mice.

Front. Cell. Neurosci. 16:802411.

doi: 10.3389/fncel.2022.802411

\section{N-3 PUFA Deficiency Affects the Ultrastructural Organization and Density of White Matter Microglia in the Developing Brain of Male Mice}

\author{
Fanny Decoeur ${ }^{1}$, Katherine Picard ${ }^{2,3,4}$, Marie-Kim St-Pierre ${ }^{2,3,4}$, Andrew D. Greenhalgh', \\ Jean-Christophe Delpech', Alexandra Sere' ${ }^{1}$, Sophie Layé1, Marie-Eve Tremblay 2,3,4,5,6t \\ and Agnès Nadjar ${ }^{1,7,8 *+}$
}

'INRAE, Bordeaux INP, NutriNeuro, Université de Bordeaux, Bordeaux, France, ${ }^{2}$ Axe Neurosciences, Centre de Recherche du CHU de Québec-Université Laval, Québec, QC, Canada, ${ }^{3}$ Division of Medical Sciences, University of Victoria, Victoria, BC, Canada, ${ }^{4}$ Département de Médecine Moléculaire, Université Laval, Québec, QC, Canada, ${ }^{5}$ Department of Neurology and Neurosurgery, McGill University, Montreal, QC, Canada, ${ }^{6}$ Department of Biochemistry and Molecular Biology, The University of British Columbia, Vancouver, BC, Canada, ${ }^{7}$ Neurocentre Magendie, U1215, INSERM-Université de Bordeaux, Bordeaux, France, ${ }^{8}$ Institut Universitaire de France (IUF), Paris, France

Over the last century, westernization of dietary habits has led to a dramatic reduction in dietary intake of n-3 polyunsaturated fatty acids (n-3 PUFAs). In particular, low maternal intake of n-3 PUFAs throughout gestation and lactation causes defects in brain myelination. Microglia are recognized for their critical contribution to neurodevelopmental processes, such as myelination. These cells invade the white matter in the first weeks of the post-natal period, where they participate in oligodendrocyte maturation and myelin production. Therefore, we investigated whether an alteration of white matter microglia accompanies the myelination deficits observed in the brain of n-3 PUFA-deficient animals. Macroscopic imaging analysis shows that maternal n-3 PUFA deficiency decreases the density of white matter microglia around post-natal day 10. Microscopic electron microscopy analyses also revealed alterations of microglial ultrastructure, a decrease in the number of contacts between microglia and myelin sheet, and a decreased amount of myelin debris in their cell body. White matter microglia further displayed increased mitochondrial abundance and network area under perinatal n-3 PUFA deficiency. Overall, our data suggest that maternal n-3 PUFA deficiency alters the structure and function of microglial cells located in the white matter of pups early in life, and this could be the key to understand myelination deficits during neurodevelopment.

Keywords: n-3 PUFA, microglia, myelin, neurodevelopment, electron microscopy

\section{HIGHLIGHTS}

- Low n-3 PUFA intake reduces white matter microglia density at key stage during development.

- Low n-3 PUFA intake reduces the interactions of white matter microglia with myelin.

- Low n-3 PUFA intake increases the abundance of mitochondria within white matter microglia. 


\section{INTRODUCTION}

The central nervous system (CNS) is mainly composed of lipids. Among these, the most abundant lipid species in the brain parenchyma are polyunsaturated fatty acids (PUFAs), more specifically arachidonic acid (AA, 20:4 n-6) and docosahexaenoic acid (DHA, 22:6 n-3) (Sastry, 1985; Rapoport et al., 2007; Betsholtz, 2015). AA and DHA can be biosynthesized from their precursors, respectively, linoleic acid (LA, 18:2 n-6) and $\alpha$-linolenic acid (ALA, 18:3 n-3), or directly provided by the diet (Lands et al., 1990). Brain accumulation of PUFAs, especially DHA, during critical periods is indispensable for CNS development and functional maturation in humans (Clandinin et al., 1980; Lauritzen et al., 2005; Innis, 2007; McNamara et al., 2017). The global reduction in dietary n-3 PUFA intake, witnessed over the last century, has led to a decrease in the brain concentration of DHA and AA (Lands et al., 1990; Innis, 2007; Koletzko et al., 2008; Bradbury, 2011; Stark et al., 2016). Low intake of n-3 PUFAs has raised concerns about its potential adverse effects on the neurological development of human infants (Koletzko et al., 2008; McNamara et al., 2015, 2017; Madore et al., 2016) resulting in an increased incidence of neurodevelopmental disorders (McNamara et al., 2015; Martinat et al., 2021).

We and others have shown that n-3 PUFA deficiency during brain development impairs microglial physiology, microgliamediated synaptic refinement, axon myelination in the white matter, neuritogenesis and neurotransmission, leading to a wide range of neurobehavioral abnormalities (Pifferi et al., 2005; Chalon, 2006; Coti Bertrand et al., 2006; Kawakita et al., 2006; Beltz et al., 2007; Cao et al., 2009; Yavin et al., 2009; Lafourcade et al., 2011; de Velasco et al., 2012; Madore et al., 2014, 2020; Leyrolle et al., 2021a). Despite these observations, the mechanisms by which n-3 PUFA deficiency affects proper CNS development, specifically myelination, require further studies.

A series of recent publications revealed a crucial microglial role in regulating myelination during neurodevelopment (Shigemoto-Mogami et al., 2014; Hagemeyer et al., 2017; Wlodarczyk et al., 2017; Hughes and Appel, 2019; Li et al., 2019; Sierra et al., 2019; Stratoulias et al., 2019; BenmamarBadel et al., 2020; Nemes-Baran et al., 2020; Tanabe and Yamashita, 2020; Traiffort et al., 2020; Fujita and Yamashita, 2021; Kalafatakis and Karagogeos, 2021). Microglia invade the white matter early after birth, during the first post-natal days in mice (Stratoulias et al., 2019; McNamara and Miron, 2020). Depleting the brain of microglia at this developmental period impairs the proper formation of oligodendrocyte progenitors (OPCs) and reduces post-natal myelination (Hagemeyer et al., 2017). Microglia sustain myelination by releasing growth factors such as the insulin-like growth factor 1 (IGF-1) and galectin-3, which promote the survival, differentiation and maturation of OPCs (Pasquini et al., 2011; Miron et al., 2013; Pang et al., 2013; Wlodarczyk et al., 2017). They also contribute to white matter formation by phagocyting fragments of myelin sheaths, or by engulfing supernumerary OPCs, two essential processes for normal brain myelination (Liu et al., 2013; Hughes and Appel, 2019; Nemes-Baran et al., 2020).
Based on previous results, we hypothesized that the defects in myelination observed in the white matter of n-3 PUFA deficient pups could result from an impairment of white matter microglia. To test this hypothesis, we analyzed the impact of n-3 PUFA deficiency on microglia in the developing white matter. We first quantified microglial density in the main white-matter tract within the brain, the corpus callosum, of the offspring across different post-natal ages (P0, P5, P10, and P15). We found a significant reduction in the number of white matter microglia in the brain of n-3 PUFA deficient mice at P10. We further characterized the ultrastructure of the corpus callosum microglial population at P10, using qualitative and quantitative transmission electron microscopy analyses. We observed significantly fewer contacts between microglia and myelinated axons, as well as fewer myelin fragments within microglial cells under n-3 PUFA deficiency. These findings were correlated with an increase in the abundance of mitochondria in microglial cells, but not of the ultrastructure of this organelle. In conclusion, our results suggest that maternal n-3 PUFA deficiency alters the structure of microglial cells located in the developing corpus callosum, as well as their interactions with the local environment.

\section{EXPERIMENTAL PROCEDURE}

\section{Animals}

All experiments were approved and performed under the guidelines of the local and national ethics committee for care and use of animals (Direction Départementale de la Protection des Animaux, approval ID: A33-063-920, \#15517) and carried out according to the Quality Reference System of INRAE and the Directive 2010/63/EU. Every effort was made to minimize the number of animals used (Janvier Labs, France) and their suffering. CD1 mice were maintained in standard cages in mixed litter with a $12 \mathrm{~h}$ light-dark cycle, temperature and humidity controlled, and food and water provided ad libitum. To reduce the use of animals, the same brains were studied for light and electron microscopy, $n=4-6 /$ group. Litter size at birth is around 12 pups per dam. CD1 juvenile (P0, P5, P10, P15) males were used for the experiments as our previous results, where we observed myelination alterations, were also obtained in male mice (Leyrolle et al., 2021b). Moreover, the literature on microglia/myelin interactions focuses on males (Hagemeyer et al., 2017; Hughes and Appel, 2019; Li et al., 2019).

\section{Diet}

During gestation and lactation, CD1 dams (obtained from Janvier Labs at 2 months of age) were fed with isocaloric diets (from INRAE Jouy en Josas) containing 5\% fat with low (n-3 PUFA sufficient group) or high (n-3 PUFA deficient group) $n-6 / n-$ 3 precursor ratio, respectively, $\alpha$-linolenic acid (ALA, 18:3 n3 ) and linoleic acid (LA, 18:2 n-6) (detailed composition is reported in Tables 1, 2), according to the international nutritional recommendations and as previously published (Delpech et al., 2015; Labrousse et al., 2018; Decoeur et al., 2020; Madore et al., 2020; Leyrolle et al., 2021a,b). We could not observe any effect 
TABLE 1 | Fatty acid composition of the dietary lipids (\% by weight of total fatty acids).

\begin{tabular}{|c|c|c|}
\hline Diets & Sufficient & Deficient \\
\hline $16: 00$ & 22.6 & 6.2 \\
\hline $18: 00$ & 3.3 & 4.4 \\
\hline Other saturated FAs & 1.8 & 1.6 \\
\hline Total saturated FAs & 27.7 & 12.2 \\
\hline $16: 1 n-7$ & 0.2 & 0.1 \\
\hline $18: 1 n-9$ & 57.9 & 26.0 \\
\hline $18: 1 n-7$ & 1.5 & 0.9 \\
\hline Other monounsaturated FAs & 0.4 & 0.2 \\
\hline Total monounsaturated FAs & 60.0 & 27.2 \\
\hline $18: 2 n-6(L A)$ & 10.6 & 60.5 \\
\hline $20: 4 n-6(A A)$ & ND & ND \\
\hline Total n-6 PUFAs & 10.7 & 60.5 \\
\hline 18:3n-3 (ALA) & 1.6 & 0.1 \\
\hline $18: 4 n-3$ & ND & ND \\
\hline $20: 5 n-3$ & ND & ND \\
\hline $22: 5 n-3$ & ND & ND \\
\hline 22:6n-3 (DHA) & ND & ND \\
\hline Total n-3 PUFAs & 1.6 & 0.1 \\
\hline total PUFAs & 12.3 & 60.6 \\
\hline$n-6 / n-3$ & 6.7 & $>500$ \\
\hline
\end{tabular}

FAs, fatty acids; $L A$, linoleic acid; $A A$, arachidonic acid; PUFAs, polyunsaturated fatty acids; ALA, $\alpha$-linolenic acid; ND, not detected (under the limit for the detection by gas)

of the diet on maternal behavior (e.g., active nursing, pups licking/sniffing, nesting) or litter size (unpublished observations. We previously reported that decreasing the amount of n-3 PUFA precursors in the maternal diet led to a significant increase in the n-6 PUFA/n-3 PUFA ratio in the pups' brain structures, white matter and microglial cells (Joffre et al., 2016; Madore et al., 2020; Leyrolle et al., 2021b).

\section{Perfusion and Cutting for Light and Electron Microscopy}

Mouse pups were anesthetized with 10\% lurocaine and 5\% exagon. Blood was intracardially flushed with ice-cold phosphatebuffered saline solution ( $\mathrm{pH}$ 7.4, $50 \mathrm{mM}$ ) (PBS) followed by a fixation with a $0.2 \%$ glutaraldehyde in $4 \%$ paraformaldehyde (PFA, Sigma) solution. Brains were extracted and post-fixed in $4 \%$ PFA at $4^{\circ} \mathrm{C}$ for $3 \mathrm{~h}$.

Total of $50-\mu \mathrm{m}$ coronal brain sections (Bregma -0.18 to -2.55) were generated using a vibratome (Leica VT1000 S) and stored at $-20^{\circ} \mathrm{C}$ in a cryoprotectant solution (30\% glycerol and $30 \%$ ethylene glycol in PBS) prior to the experiments.

\section{Iba1 (Ionized Calcium-Binding Adapter Molecule 1) Immunostaining and Analyses by Light Microscopy}

Briefly, free-floating sections containing the region of interest (corpus callosum) were washed and quenched for $30 \mathrm{~min}$ in $0.3 \% \mathrm{H}_{2} \mathrm{O}_{2}$ in $\mathrm{H}_{2} \mathrm{O}$. Sections were incubated in a blocking buffer (BB) solution (3\% bovine serum albumin, $0.3 \%$ Triton
X-100 in PBS) at room temperature (RT) for $1 \mathrm{~h}$. Then, samples were immunostained using a rabbit polyclonal antiIba1 primary antibody (1/1,000, Wako cat\#019-19741, Neuss, Germany) diluted in $\mathrm{BB}$ at $4^{\circ} \mathrm{C}$ overnight. The following day, the sections were washed and incubated with a biotinylated goat anti-rabbit secondary antibody (1/2,000, Invitrogen, Saint Aubin, France) for $2 \mathrm{~h}$ at RT, followed by a $1 \mathrm{~h}$ incubation in a peroxidase conjugated avidin/biotin complex solution (Vectastain ABC kit Biovalley) at RT. The staining was revealed using $0.6 \%$ diaminobenzidine (DAB) with a nickel-enhanced glucose oxidase method (Shu et al., 1988). The sections were washed, dehydrated in increasing concentrations of ethanol, mounted on slides and coverslipped using Depex mounting medium (BDH, 361254D).

Sections ( $n=4-6 /$ group) containing the corpus callosum (body; -0.18 to -2.55 to Bregma) were imaged at $20 \mathrm{X}$ using a Nanozoomer slide scanner (Hamamatsu Photonics), extracted with the NDP.view 2 freeware (Hamamatsu Photonics) and analyzed with ImageJ software. The corpus callosum area traced was calculated and the density of Ibal + cells was determined per $\mathrm{mm}^{2}$. The analysis was conducted blind to the experimental conditions. Brain sections were obtained from 6 P0 litters (for a total of $4 \mathrm{n}-3$ sufficient $=$ mice and $5 \mathrm{n}-3$ deficient mice), 5 P5 litters ( $\mathrm{n}-3$ sufficient $=4$ mice, $\mathrm{n}-3$ deficient $=4$ mice), 5 P10 litters ( $\mathrm{n}-3$ sufficient $=4$ mice, $\mathrm{n}-3$ deficient $=5$ mice $), 4$ P15 litters $(\mathrm{n}-3$ sufficient $=6$ mice, $n-3$ deficient $=5$ mice) .

\section{Iba1 Immunostaining and Ultrastructural Analysis by Electron Microscopy}

Sections containing the corpus callosum were washed with PBS then quenched in $0.3 \% \mathrm{H}_{2} \mathrm{O}_{2}$ in PBS for 5 min and permeabilized in $0.1 \% \mathrm{NaBH}_{4}$ in PBS for 30 min. Samples were incubated $1 \mathrm{~h}$ at RT in $\mathrm{BB}$ (10\% fetal bovine serum, $3 \%$ bovine serum albumin, $0.01 \%$ Triton $\mathrm{X}-100$, diluted in PBS) before immunostaining with rabbit anti-Ibal primary antibody $(1 / 1,000$ in BB; same antibody as above) overnight at $4^{\circ} \mathrm{C}$. Samples were washed in TBS and incubated with biotinylated goat anti-rabbit secondary antibody (1/300 in TBS; cat\# 111-066-046, Jackson ImmunoResearch, West Grove, PA, United States) $2 \mathrm{~h}$ at RT, followed by a peroxidase conjugated avidin/biotin complex solution (Vectastain ABC kit Biovalley) $1 \mathrm{~h}$ at RT. Immunostaining was revealed in $0.05 \% \mathrm{DAB}$ containing $0.015 \% \mathrm{H}_{2} \mathrm{O}_{2}$. Sections were washed and incubated in $3 \%$ potassium ferrocyanide in milliQ $\mathrm{H}_{2} \mathrm{O}$ combined (1:1) with 4\% (aq) osmium tetroxide (cat\# 19170, Electron Microscopy Sciences, Hatfield, PA, United States) for $1 \mathrm{~h}$, then incubated in heated $1 \%$ thiocarbohydrazide (in PBS; cat\# 2231-57-4, Electron Microscopy Sciences) diluted in milliQ $\mathrm{H}_{2} \mathrm{O}$ for $20 \mathrm{~min}$, and incubated in 2\% osmium tetroxide (diluted in $\mathrm{H}_{2} \mathrm{O}$ ) for $30 \mathrm{~min}$. Sections were dehydrated in increasing concentrations of ethanol, followed by propylene oxide. Tissues were infiltrated with Durcupan ACM resin (cat\# 44611-44614, MilliporeSigma) overnight at RT and flat-embedded between fluoropolymer sheets at $55^{\circ} \mathrm{C}$ for 5 days. The corpus callosum (body) was excised from the sections and re-embedded on resin blocks. Ultra-thin sections were cut at $70 \mathrm{~nm}$ using a Leica ARTOS 3D Ultramicrotome. Sections were collected and placed on copper square mesh grids (cat\#G150-Cu Electron Microscopy Sciences). Pictures were 
TABLE 2 | Composition of the diets ( $\mathrm{g} / \mathrm{kg}$ diet).

\begin{tabular}{lc}
\hline Ingredient & Amount \\
\hline Casein & 180 \\
Cornstarch & 460 \\
Sucrose & 230 \\
Cellulose & 20 \\
Fat ${ }^{1}$ & 50 \\
Mineral mix & 20 \\
Vitamin mix & 30 \\
\hline
\end{tabular}

${ }^{1}$ for detailed composition, see Table 1.

${ }^{2}$ composition $(\mathrm{g} / \mathrm{kg})$ : sucrose, 110.7; CaCO3, 240; K2HPO4, 215; CaHPO4, 215; MgSO4,7H2O, 100; NaCl, 60; MgO, 40; FeSO4,7H2O, 8; ZnSO4,7H2O, 7; $\mathrm{MnSO} 4, \mathrm{H} 2 \mathrm{O}, 2$; CuSO4,5H2O, 1; Na2SiO7,3H2O, 0.5; AlK(SO4)2,12H2O, 0.2; K2CrO4, 0.15; NaF, 0.1; NiSO4,6H2O, 0.1; H2BO3, 0.1; CoSO4,7H2O, 0.05; KIO3, 0.04; (NH4)6Mo7O24,4H2O, 0.02; LiCl, 0.015; Na2SeO3, $0.015 ;$ NH4VO3, 0.01.

${ }^{3}$ composition (g/kg): sucrose, 549.45; retinyl acetate, 1; cholecalciferol, 0.25; DLa-tocopheryl acetate, 20; phylloquinone, 0.1 ; thiamin $\mathrm{HCl}, 1$; riboflavin, 1 ; nicotinic acid, 5; calcium pantothenate, 2.5; pyridoxine $\mathrm{HCl}$, 1; biotin, 1; folic acid, 0.2; cyanobalamin, 2.5; choline HCl, 200; DL-methionin, 200; p-aminobenzoic acid, 5; inositol, 10.

acquired at a magnification of X10000 under a JOEL JEM-1400 transmission electron microscope operated at $80 \mathrm{kV}$ using a Gatan SC-1000 digital camera (11 Megapixel CCD camera).

Images of 8 to 12 microglial cell bodies per animal $(n=63-$ 65 microglia/diet, $N=6 \mathrm{mice} /$ group) were analyzed by an experimenter blinded to the experimental conditions using ImageJ. Microglial cell bodies were recognized by their Ibal-immunopositive $(+)$ cytoplasm (dark staining, dense to electrons), nuclear hetero- and euchromatin pattern characteristic of these cells, as well as long and narrow cisternae of endoplasmic reticulum (ER), among other distinctive features (Tremblay et al., 2010; Nahirney and Tremblay, 2021). Microglial cells are phagocytes and therefore it is common to find inclusions in their cytoplasm. Microglia organelles are distributed everywhere in the cytoplasm, unlike oligodendrocytes, whose organelles tend to be arranged in one place. Ultrastructural analyses of microglial cell bodies were performed, determining their: (1) shape: area, perimeter, circularity (area-to-perimeter ratio), aspect ratio (ratio of the objects height to width), roundness (is defined by the ratio of the area of an object to the area of a circle with the same convex perimeter; excludes local irregularities) and solidity (density of an object, area-to-convex area ratio); (2) organelle number: ER, Golgi apparatus, lysosomes, empty phagosomes with a diameter larger than $100 \mathrm{~nm}$, phagosomes containing parenchymal elements including myelin and mitochondria; (3) organelles anomalies: dilation of the ER and Golgi apparatus, alteration or elongation of mitochondria; (4) parenchymal interactions: contacts with axon terminals, dendritic spines, myelinated axons, astrocytic and neuronal cell bodies. Dendritic spines are recognized by their postsynaptic density and axon terminals by their synaptic vesicles. To analyze the contacts with excitatory synapses (combination of both a pre- and a post-synapse), we considered the elements directly juxtaposing the microglial cell bodies. Previously described identification criteria were used for
TABLE 3 | Quantification of ultrastructural parameters in P10 mice.

\begin{tabular}{|c|c|c|c|}
\hline & $n-3$ sufficient & n-3 deficient & $p$-value \\
\hline Nucleus area $\left(\mu \mathrm{m}^{2}\right)$ & 14.31 & 16.62 & 0.16 \\
\hline Cytoplasmic area $\left(\mu \mathrm{m}^{2}\right)$ & 7.48 & 8.93 & 0.02 \\
\hline Nucleus perimeter ( $\mu \mathrm{m})$ & 17.22 & 18.88 & 0.16 \\
\hline Cytoplasmic perimeter ( $\mu \mathrm{m})$ & 26.36 & 29.47 & 0.27 \\
\hline Circularity & 0.66 & 0.63 & 0.1 \\
\hline Aspect Ratio & 2.11 & 2.07 & 0.63 \\
\hline Roundness & 0.47 & 0.48 & 0.67 \\
\hline Solidity & 0.95 & 0.95 & 0.71 \\
\hline Phagosomes per cell $(n)$ & 2 & 1 & 0.27 \\
\hline ER dilation (\% of cells) & 0 & 0 & 0.4 \\
\hline Golgi dilation ( $\%$ of cells) & 0 & 0 & 0.24 \\
\hline Myelin debris per cell $(n)$ & 0 & 0 & 0.01 \\
\hline Mitochondria per cell $(n)$ & 3 & 5 & 0.001 \\
\hline $\begin{array}{l}\text { Elongated mitochondria per cell } \\
(n)\end{array}$ & 0 & 0 & 0.80 \\
\hline Altered mitochondria per cell $(n)$ & 0 & 0 & 0.16 \\
\hline $\begin{array}{l}\text { Percent cytoplasm occupied by } \\
\text { mitochondria (\% of area) }\end{array}$ & 3.62 & 6.20 & 0.002 \\
\hline $\begin{array}{l}\text { Contact with myelinated axon } \\
\text { per cell }(n)\end{array}$ & 0 & 0 & 0.02 \\
\hline $\begin{array}{l}\text { Contact with oligodendrocyte } \\
\text { per cell }(n)\end{array}$ & 0 & 0 & 0.55 \\
\hline $\begin{array}{l}\text { Contact with astrocyte per cell } \\
\text { (n) }\end{array}$ & 0 & 0 & $>0.99$ \\
\hline Contact with neuron per cell (n) & 0 & 0 & $>0.99$ \\
\hline $\begin{array}{l}\text { Contact with pre-synapse per } \\
\text { cell }(n)\end{array}$ & 1 & 0 & 0.18 \\
\hline $\begin{array}{l}\text { Contact with post-synapse per } \\
\text { cell }(n)\end{array}$ & 0 & 0 & 0.07 \\
\hline $\begin{array}{l}\text { Contact with pre- and } \\
\text { post-synapse per cell (n) }\end{array}$ & 0 & 0 & 0.60 \\
\hline
\end{tabular}

a.u., arbitrary unit; statistical significance was set to $p<0.05$.

The results are expressed as median \pm SEM.

Non-parametric unpaired two-tailed Student's t-tests were applied for all analyses.

the ultrastructural analysis (Bisht et al., 2016; Chavez-Valdez et al., 2016; El Hajj et al., 2019; St-Pierre et al., 2019; Lecours et al., 2020; Savage et al., 2020; Bordeleau et al., 2021; Nahirney and Tremblay, 2021). For instance, mitochondria were recognized by their double-membrane, their oval shape and electron-dense appearance with the presence of cristae. We analyzed the percent area occupied by the overall mitochondrial network (cytoplasmic fraction containing mitochondria). Altered mitochondria were identified by their swollen appearance, broken cristae, as well as holy-shape or elongated form (more than 1,000 nm long). The ER cisternae were distinguished by their long and narrow shape, while the Golgi apparatus is shorter, circular and appeared as a stack of elongated circular profiles on top of each other. Phagosomes were identified by their defined electron-dense membrane containing parenchymal elements including myelin. Myelinated axons were characterized by their electron-lucent cytoplasm surrounded by electron-dense sheaths (Lampron et al., 2015; Nahirney and Tremblay, 2021). Oligodendrocyte cell bodies were recognized by their electron-dense cytoplasm with patchy heterochromatin pattern and organelles were generally 
distributed to one side of the cell. Neuronal cell bodies were identified by a granular appearance of their electron-lucent (light gray) nucleo- and cytoplasm. These cells were circular and much larger than other brain cells. Astrocyte cell bodies were recognized by their electron-lucent cyto- and nucleoplasm with angular shaped protrusions from the plasma membrane and the presence of intermediary filaments (Bisht et al., 2016; Chavez-Valdez et al., 2016; El Hajj et al., 2019; St-Pierre et al., 2019; Lecours et al., 2020; Savage et al., 2020; Bordeleau et al., 2021; Nahirney and Tremblay, 2021).

\section{Statistical Analyses}

All statistical analyses were performed by using Prism 9 (GraphPad software). The results are expressed as mean \pm standard error of the mean (SEM), except Table 3 which presents medians. Statistical significance was set to $p<0.05$. Normality and homoscedasticity were verified using the ShapiroWilk test and Brown-Forsythe test, respectively. Non-parametric unpaired two-tailed Student's $t$-tests were applied for all analyses that did not pass normality and/or homoscedasticity. None of the microglial ultrastructure parameters presented in Table 3 pass normality using Shapiro-Wilk test. They were analyzed by non-parametric two-tailed Student's unpaired $t$-tests. The analysis of microglial properties was usually conducted using $n=$ cell considering the biological unit as the microglia, and not the animal. This is similar to what is done with other cell types including microglia and their compartments by our group and others (Hellwig et al., 2016; Milior et al., 2016; Lecours et al., 2020).

\section{RESULTS}

\section{Dietary n-3 PUFA Deficiency Affects Microglial Density in the Developing Corpus callosum}

We first quantified the number of white matter microglia using Ibal immunostaining in the corpus callosum of n-3 sufficient and n-3 deficient mice, at post-natal ages P0, P5, P10, and P15, i.e., when microglia are expected to invade the white matter (Hagemeyer et al., 2017). Ibal + microglial cell density was similar between both dietary groups at P0, P5, and P15. However, n-3 deficient mice displayed less Iba1 + cells at P10, compared to control animals (Figures 1A,B) (P10 n-3 sufficient vs n-3 deficient: Unpaired $t$-test: $\left.t=2,701 \mathrm{df}=7,{ }^{*} p=0.0306\right)$. While we cannot firmly conclude on the total number of microglia, this shows that n-3 PUFA deficiency affects microglial cell density in the white matter, at a key stage of neurodevelopment, and highlights temporal abnormalities in the post-natal colonization of the corpus callosum by microglia.

\section{N-3 PUFA Deficiency Reduces Microglial Interactions With Myelin in the Developing Corpus callosum}

To study at nanoscale resolution whether and how white matter microglia of the corpus callosum interact with their microenvironment, we conducted transmission electron microscopy imaging and analyses on brain slices from P10 pups (based on our previous observation of microglial density differences). We quantified the number of contacts between microglia and myelinated axons, axon terminals, dendritic spines, oligodendrocytes, astrocytes, and neurons (Table 3). While most of the parameters studied were not significantly different between n-3 sufficient and n-3 deficient mice (Table 3 ), we observed a significant decrease in the number of contacts per cell between microglia and myelinated axons (Figures 2A,B and Table 3) (n-3 sufficient $v s$ n-3 deficient: Mann-Whitney test $* p=0.0227)$. Moreover, $29 \%$ of microglia contacted myelinated axons in the n-3 sufficient condition vs $14 \%$ in $n-3$ deficient mice (data not shown). We also assessed the number of myelin fragments per microglial cell body and found significantly less myelin debris in microglia from $\mathrm{n}-3$ deficient mice (Figures 2A,C and Table 3) (n-3 sufficient vs n-3 deficient: Mann-Whitney test $* * p=0.009)$. These data indicate that not only are there fewer microglia, but low n-3 PUFA intake affected the interaction of microglia with myelin in the corpus callosum.

\section{N-3 PUFA Deficiency Increases Microglial Abundance of Mitochondria in the Developing Corpus callosum}

To further characterize the ultrastructure of white matter microglia, we quantified their cellular content in the corpus callosum of P10 pups, including mitochondria, an intracellular organelle whose primary function is to provide the energy that microglia need to survive. It has been recently shown that microglia control their states and functional properties by adapting intracellular metabolic pathways to their energy requirements (Nadjar, 2018; Borst et al., 2019; Paolicelli and Angiari, 2019; Lauro and Limatola, 2020). Microglial cell bodies exposed to n-3 PUFA deficient diet displayed a significant increase in the number of mitochondria (Figures $\mathbf{3 A}-\mathbf{C}$ and Table 3) (n-3 sufficient vs n-3 deficient: mitochondria, MannWhitney test $* * * p=0.0008)$. Since we observed an increase of microglial cytoplasmic area (Table 3) (n-3 sufficient vs n3 deficient: Mann-Whitney test $\left.{ }^{*} p=0.0239\right)$, and to avoid any bias, we then analyzed the percent area occupied by the overall mitochondrial network (cytoplasmic fraction containing mitochondria). N-3 PUFA deficient diet caused a significant increase in the mitochondrial network area (Figures 3A-D and Table 3) (n-3 sufficient vs n-3 deficient: percent cytoplasm containing mitochondria, Mann-Whitney test ${ }^{* *} p=0.0023$ ). This was not accompanied by an increase in markers of cellular stress in the mitochondria (Altered mitochondria can be identified by their swollen appearance, broken cristae, showing a holy-shape and elongated form, more than 1,000 nm long) (Table 3). These observations suggest an alteration of microglial energy metabolism under n-3 PUFA deficiency, in the corpus callosum of P10 pups. We also studied other microglial organelles including the ER, phagosome and Golgi apparatus. The morphology of these organelles was not significantly different between n-3 sufficient and n-3 deficient mice (Table 3). 

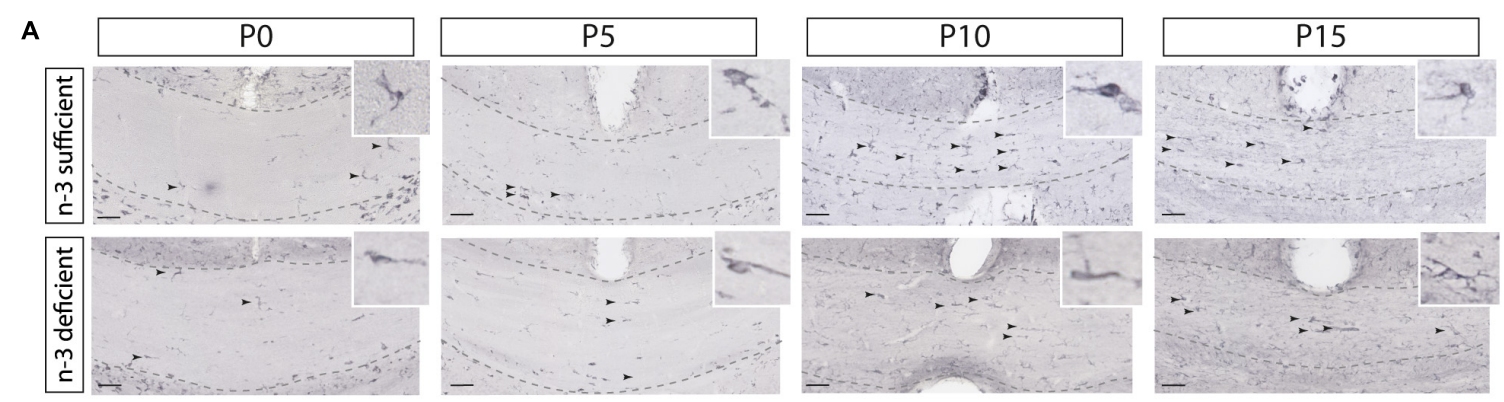

B

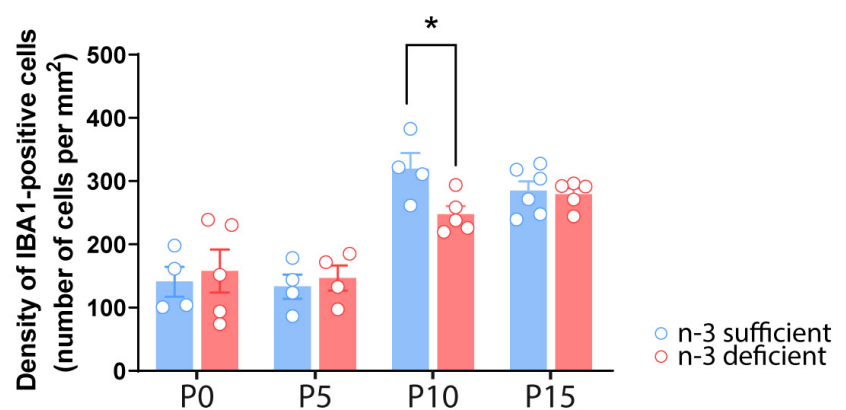

FIGURE 1 | Dietary n-3 PUFA deficiency decreases microglial density in the developing corpus callosum. (A) Representative images of lba1-positive cells (arrow) at different post-natal ages (P0, P5, P10, and P15) in the corpus callosum of $n-3$ sufficient and $n-3$ deficient mice (scale bar $=50 \mu \mathrm{m}$; dotted lines delineate the corpus callosum). (B) Result of the quantification of Iba1-positive cell density, at different post-natal ages (P0, P5, P10, and P15) in the corpus callosum of n-3 sufficient and $\mathrm{n}-3$ deficient mice. All data are presented as mean \pm SEM. Blue bars/circles $=n-3$ sufficient mice, red bars/circles $=n-3$ deficient mice. $n=4-6$ animals/group. ${ }^{*} p<0.05$.

\section{DISCUSSION}

Overall, our results showed that maternal n-3 PUFA deficiency affects white matter microglia in the early post-natal offspring. We observed a decrease in Ibal + microglial density in the corpus callosum at P10, together with less microglial contacts with myelin, less internalized myelin fragments and increased abundance and area of mitochondria. We acknowledge the need to study females in a follow-up study, considering the described sexual dimorphism of microglia and myelination processes (Cerghet et al., 2009; Han et al., 2021).

We previously observed that microglia from the gray matter are affected by n-3 PUFA deficiency at P21 (Madore et al., 2014, 2020). More specifically, we showed that microglia located in the hippocampus are profoundly altered in their lipid composition (less n-3 PUFAs and more n-6 PUFAs in their membranes), in their physiology (more prone to react to inflammatory stimuli, more phagocytic) and in their motility (processes are less motile), when exposed to low n-3 PUFAs (Madore et al., 2014, 2020). We also revealed that these modifications are causal to the neuronal deficits observed in n-3 deficient mice, including impairment of spatial working memory (Madore et al., 2020). In the present study, we observed that microglia located in the white matter are also compromised in the offspring at P10, when maternal n-3 PUFA dietary intake is low, affecting the ultrastructural organization and density of the white matter microglial population among the corpus callosum. We chose the latter based on the previous studies on myelin/microglia interactions during development (Hagemeyer et al., 2017; Kaur et al., 2017; Lee et al., 2019; NemesBaran et al., 2020; Traiffort et al., 2020). This is also in this area that we observed an alteration of myelination in mice deficient in n-3 PUFA in a former study (Leyrolle et al., 2021b). We focused on one part of the corpus callosum, the body that unites the motor, somatosensory and parietal regions (Wahl et al., 2007; Park et al., 2008; Putnam et al., 2010; Ku and Torii, 2020). More experiments are needed to fully unravel to what extent n-3 PUFA deficiency affects microglial morphology, lipid composition and functions in the corpus callosum and how this would relate to behavior abnormalities later in life.

Our data reveal that n-3 deficient mice did not display the peak in microglial density classically observed at P10. Indeed, according to the literature, microglia invade the corpus callosum of mice, a phenomenon called the "fountain of microglia" (Del Rio-Hortega and Penfield, 1932; Imamoto and Leblond, 1978; Ling, 1979), with a peak around that age, to promote adequate induction of oligodendrocytes (Hagemeyer et al., 2017; Wlodarczyk et al., 2017). A reversible depletion of microglia during this time frame reduces the total number of mature oligodendrocytes at P20, even if the total number of microglia is back to normal at that age (Hagemeyer et al., 2017). This suggests that the peak of microglial invasion occurring at P10 is essential for proper myelination of the brain. In line with this assumption, Kalafatakis and Karagogeos, 2021 have shown that the time course of microglial migration to the white matter correlates with the onset of OPCs generation in this structure. 

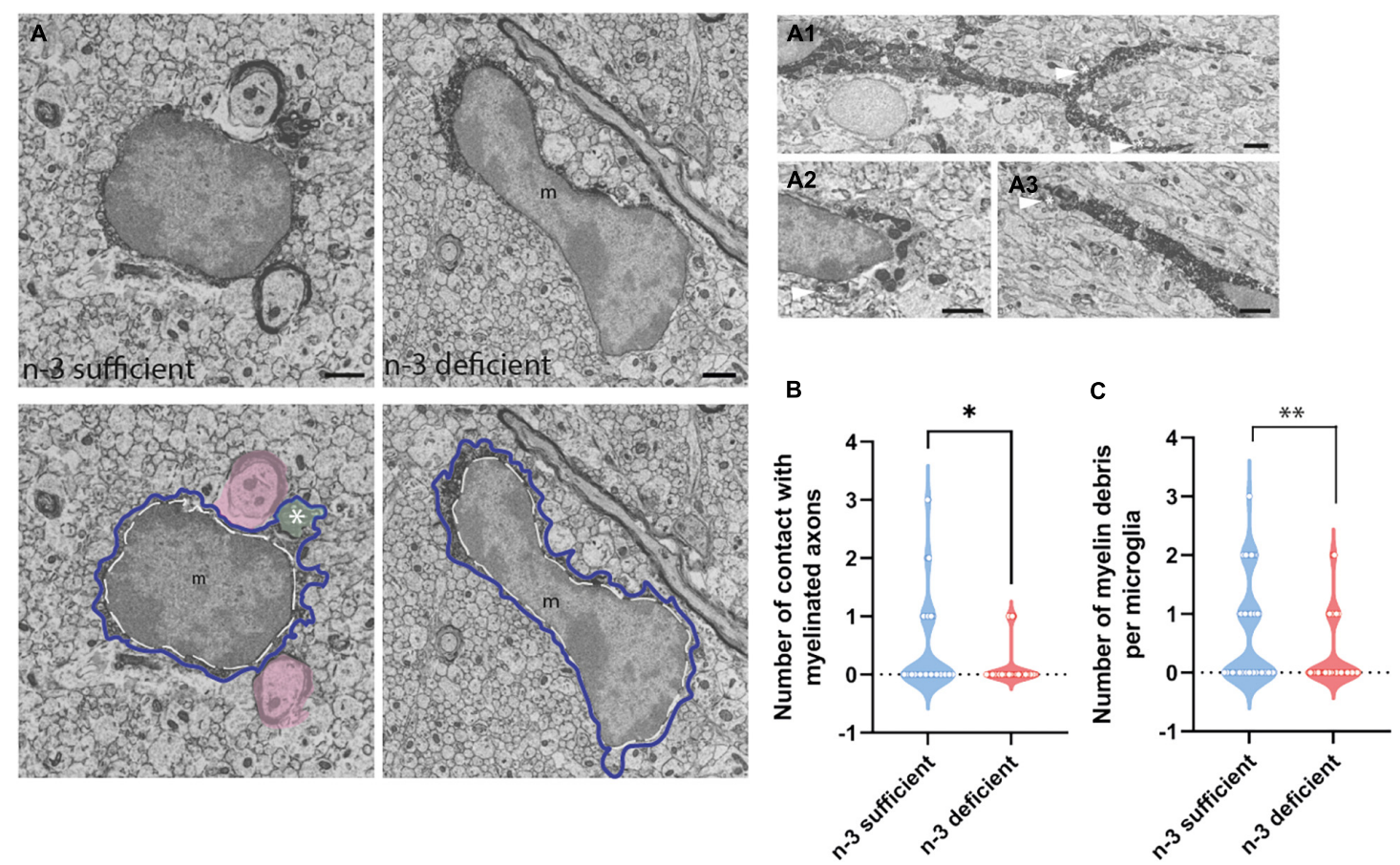

FIGURE 2 | N-3 PUFA deficiency reduces the number of contacts between microglia and myelin axon and decreases the presence of myelin fragments in microglia. (A) Representative images of microglial ultrastructure in the corpus callosum of P10 mice (left panel: n-3 sufficient, right panel: n-3 deficient; upper panels: original images, lower panels: with false colors), showing interactions between microglial cell bodies and myelinated axons (in pink), as well as myelin debris (green, see asterisk) in the cytoplasm of the cell (magnification: 10,000x) (scale bar $=1 \mu \mathrm{m})$. More examples of microglia engulfing myelin debris (see asterisk and arrowhead) in A1-A3; Scale bar $=1 \mu \mathrm{m}$. Microglia are annotated with "m," the contour of their nucleus is delineated with a white dotted line and the cytoplasm by a purple line.

(B) Quantification of the number of myelinated axons in contact with microglia in both dietary groups. (C) Quantification of number of myelin debris in microglial cells, in both dietary groups. All data are presented as mean \pm SEM. $n=63-65$ microglia/group, $N=6$ mice/group.

Interestingly, we previously demonstrated that maternal n-3 PUFA deficiency leads to hypomyelination of the corpus callosum at P21 and in the adult offspring, and to a significant decrease in the number of mature oligodendrocytes in the corpus callosum of juveniles, associated with long-term deficits in brain structures synchronization (Leyrolle et al., 2021b). Hence, while the total number of microglia was similar between both dietary groups at $\mathrm{P} 15$, the absence of a peak at P10 in $\mathrm{n}-3$ deficient mice may have significant functional impacts. More studies are needed to fully test this hypothesis.

During development, white matter microglia phagocytose excess myelin sheaths in an activity-dependent manner, a key process for optimal myelination (Hughes and Appel, 2019; Zareba and Peri, 2021). Here, we observed that microglia from n-3 deficient animals contained less myelin fragments and were interacting less with myelinated axons. This finding suggests that myelin turnover is less efficient in these animals, which might explain our previous result that n-3 PUFA deficiency decreases myelin thickness in the corpus callosum of mouse pups, resulting in a long-term decrease of brain functional connectivity (Leyrolle et al., 2021b). In line with this assumption, we previously showed that treating mouse pups with clemastine, a first-generation histamine antagonist and pro-myelinating agent, could restore OPCs density in the corpus callosum of $\mathrm{n}-3$ deficient mice (Leyrolle et al., 2021b). The mechanisms of action of clemastine are still a matter of debate. Indeed, clemastine could promote OPCs maturation and proliferation, not only via a direct action, but also via signaling through M1 muscarinic receptors expressed by microglia (Cree et al., 2018; Lloyd and Miron, 2019). In turn, microglia could promote OPCs maturation and myelination (Shigemoto-Mogami et al., 2014; Su et al., 2018; Xie et al., 2020). More studies are needed to understand whether the reduced uptake of myelin debris by microglia that we found in $n-3$ deficient mice is responsible for the deficits in myelin previously observed in these animals (Leyrolle et al., 2021b).

Polyunsaturated fatty acids have been shown to regulate mitochondrial properties and functions including calcium homeostasis, mitochondrial gene expression, respiratory function, reactive oxygen species production, mitochondrial apoptosis and biogenesis (Flachs et al., 2005; Rohrbach, 2009; Lanza et al., 2013; Afshordel et al., 2014; de Oliveira et al., 2017; Isesele and Mazurak, 2021). Still under debate, these findings reveal a link between PUFAs and mitochondrial physiology, which is supported by an increase in the abundance of mitochondria within white matter microglia without affecting other organelles.

In the last decade, the ground-breaking field of immunometabolism has grown exponentially, providing new understanding of how immune cells control their states and functional properties by adapting intracellular metabolic 

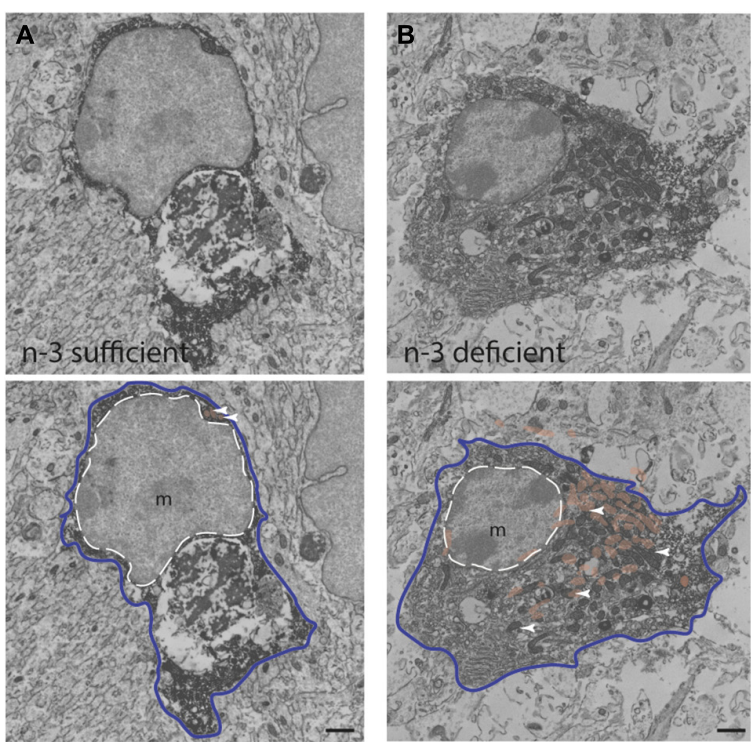

C
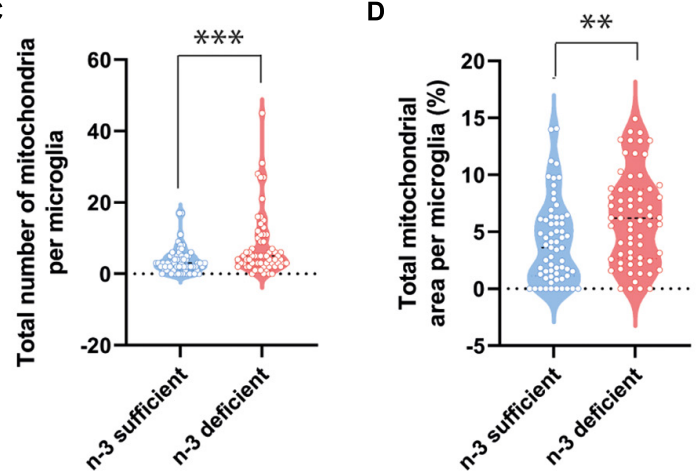

FIGURE 3 | N-3 PUFA deficiency increases mitochondrial abundance and area in microglia at P10. (A,B) Representative images of microglial ultrastructure in the corpus callosum of P10 mice, showing the abundance of mitochondria (upper panels: original images, lower panels: with false colors: e.g., mitochondria in orange + white arrowheads) (magnification: 10,000 $x$ ) (scale bar $=1 \mu \mathrm{m}$ ) in $\mathrm{n}-3$ sufficient mice $\mathbf{( A )}$ and $\mathrm{n}-3$ deficient mice (B) Microglia are annotated with " $m$," the contour of their nucleus is delineated with a white dotted line and the cytoplasm by a purple line. Mitochondria are highlighted in false color (light brown). (C) Quantification of number of mitochondria in microglia cells from both dietary groups. (D) The percent of cytoplasm containing mitochondria in both dietary groups. All data are presented as mean \pm SEM. $n=63-65$ microglia/group, $N=6$ animals/group. ${ }^{* \star} p<0.01,{ }^{* \star \star} p<0.001$.

pathways to their needs in energy (O’Neill et al., 2016; Borst et al., 2019; Paolicelli and Angiari, 2019). Emerging evidence suggests that any phenotypic shift of microglia relies onto a metabolic reprogramming of the cells (Nadjar, 2018; Borst et al., 2019; Paolicelli and Angiari, 2019). Our data showed a decreased number of myelin debris within microglia, suggestive of altered phagocytic activity, associated with an increase in the number of mitochondria. To date, there is limited data on the metabolic shift associated to microglial phagocytosis. In vitro evidence, however, suggest that the modulation of phagocytosis relies on mitochondrial oxidative phosphorylation (Gimeno-Bayón et al.,
2014; Orihuela et al., 2016). Hence, the increase in mitochondrial number observed in n-3 deficient mice might sustain the modulation of their phagocytic activity.

In conclusion, we uncovered a novel effect of maternal n3 PUFA dietary deficiency on white matter microglia in the developing brain. Further studies are needed to (1) understand the mechanism by which n-3 PUFA affect white matter microglia during neurodevelopment, and (2) test for the causal link between white matter microglia alterations and the myelination deficits that are observed in n-3 deficient mice.

\section{DATA AVAILABILITY STATEMENT}

The original contributions presented in the study are included in the article/supplementary material, further inquiries can be directed to the corresponding author/s.

\section{ETHICS STATEMENT}

The animal study was reviewed and approved by Direction Départementale de la Protection des Animaux, approval ID: A33-063-920, \#15517.

\section{AUTHOR CONTRIBUTIONS}

FD, KP, AS, M-KS-P, AG, and J-CD performed all the experiments. FD, KP, and AS performed the mice perfusion. AG and J-CD supervised part of the experiments. FD and KP performed the immunochemistry staining and tissue preparation for the electron microscopy. FD, KP, and M-KS-P cut the sample for electron microscopy. FD performed the electron microscopy imaging and analyzed the acquired images with the help of M-KS-P. SL provided part of the financial support and facilities necessary for the project. AN and M-ET led the entire project. AN, M-ET, and FD wrote the manuscript. All authors proofread the manuscript.

\section{FUNDING}

This research was funded by the Institut National pour la Recherche Agronomique, l'Alimentation et l'Environnement (INRAE), the Bordeaux Univ and the International Laboratory OptiNutriBrain. AN was supported by the Region Ile de France (PICRI, the Cerebral Palsy Foundation \#13020605) and by the FRM. M-ET holds a Canada Research Chair (Tier 2) in Neurobiology of Aging and Cognition. AN and M-ET were supported by the Fonds de Recherche du Québec- Nature et Technologie (FRQNT). SL was supported by the Foundation for Medical Research (FRM, DEQ20170336724), the French Foundation (FDF, \#00070700), Fondation pour la Recherche sur le Cerveau (FRC), Fondation Carrefour and Région Nouvelle Aquitaine. FD was funded by Idex/University of Bordeaux and benefited from the Bordeaux Neurocampus Graduate Program (EUR 17-EURE-0028 project). KP was supported by a doctoral scholarship from Fonds de recherche du Québec-Santé (FRQS). 
M-KS-P was supported by a doctoral training award from the Canadian Institutes of Health Research (CIHR) and a Fond de Recherche du Québec-Santé (FRQS) doctoral award. Bordeaux Imaging Center a service unit of the CNRS-INSERM and Bordeaux University, member of the national infrastructure France BioImaging, are supported by the French National Research Agency (ANR-10-INBS-04).

\section{ACKNOWLEDGMENTS}

We would like to thank Patrick Nahirney and Brent Gowen for the access to the transmission electron microscope. We would

\section{REFERENCES}

Afshordel, S., Hagl, S., Werner, D., Milosch, N., Kögel, D., Bazan, N., et al. (2014). Omega-3 Polyunsaturated Fatty Acids improve mitochondrial dysfunction in brain aging - impact of Bcl-2 and NPD-1 like metabolites. Prostaglandins Leukot. Essent. Fatty Acids 92, 23-31. doi: 10.1016/j.plefa.2014.05.008

Beltz, B. S., Tlusty, M. F., Benton, J. L., and Sandeman, D. C. (2007). Omega3 fatty acids upregulate adult neurogenesis. Neurosci. Lett. 415, 154-158. doi: 10.1016/j.neulet.2007.01.010

Benmamar-Badel, A., Owens, T., and Wlodarczyk, A. (2020). Protective microglial subset in development, aging, and disease: lessons from transcriptomic studies. Front. Immunol. 11:430. doi: 10.3389/fimmu.2020.00430

Betsholtz, C. (2015). Lipid transport and human brain development. Nat. Genet. 47, 699-701. doi: 10.1038/ng.3348

Bisht, K., Sharma, K. P., Lecours, C., Gabriela Sánchez, M., El Hajj, H., Milior, G., et al. (2016). Dark microglia: a new phenotype predominantly associated with pathological states. Glia 64, 826-839. doi: 10.1002/glia.22966

Bordeleau, M., Fernández de Cossío, L., Lacabanne, C., Savage, J. C., Vernoux, N., Chakravarty, M., et al. (2021). Maternal high-fat diet modifies myelin organization, microglial interactions, and results in social memory and sensorimotor gating deficits in adolescent mouse offspring. Brain Behav. Immun. Health 15:100281. doi: 10.1016/j.bbih.2021.100281

Borst, K., Schwabenland, M., and Prinz, M. (2019). Microglia metabolism in health and disease. Neurochem. Int. 130:104331. doi: 10.1016/j.neuint.2018.11.006

Bradbury, J. (2011). Docosahexaenoic acid (DHA): an ancient nutrient for the modern human brain. Nutrients 3, 529-554. doi: 10.3390/nu305 0529

Cao, D., Kevala, K., Kim, J., Moon, H.-S., Jun, S. B., Lovinger, D., et al. (2009). Docosahexaenoic acid promotes hippocampal neuronal development and synaptic function. J. Neurochem. 111, 510-521. doi: 10.1111/j.1471-4159.2009. 06335.x

Cerghet, M., Skoff, R. P., Swamydas, M., and Bessert, D. (2009). Sexual dimorphism in the white matter of rodents. J. Neurol. Sci. 286, 76-80. doi: 10.1016/j.jns.2009. 06.039

Chalon, S. (2006). Omega-3 fatty acids and monoamine neurotransmission. Prostaglandins Leukot. Essent. Fatty Acids 75, 259-269. doi: 10.1016/j.plefa. 2006.07.005

Chavez-Valdez, R., Flock, D. L., Martin, L. J., and Northington, F. J. (2016). Endoplasmic reticulum pathology and stress response in neurons precede programmed necrosis after neonatal hypoxia-ischemia. Int. J. Dev. Neurosci. 48, 58-70. doi: 10.1016/j.ijdevneu.2015.11.007

Clandinin, M. T., Chappell, J. E., Leong, S., Heim, T., Swyer, P. R., and Chance, G. W. (1980). Intrauterine fatty acid accretion rates in human brain: implications for fatty acid requirements. Early Hum. Dev. 4, 121-129. doi: 10.1016/0378-3782(80)90015-8

Coti Bertrand, P., O’Kusky, J. R., and Innis, S. M. (2006). Maternal dietary (n-3) fatty acid deficiency alters neurogenesis in the embryonic rat brain. J. Nutr. 136, 1570-1575. doi: 10.1093/jn/136.6.1570

Cree, B. A. C., Niu, J., Hoi, K. K., Zhao, C., Caganap, S. D., Henry, R. G., et al. (2018). Clemastine rescues myelination defects and promotes functional recovery in hypoxic brain injury. Brain 141, 85-98. doi: 10.1093/brain/awx312 also like to thank Christel Poujol, Sébastien Marais, Fabrice Cordelières, Jérémie Teillon, Magali Mondin, Monica FernandezMonreal from the Bordeaux Imaging Center (Bordeaux, France) for their help with microscopy experiments and image analysis. We like to thank Maude Bordeleau for her help with image analyses. We finally thank the animal facility of the NutriNeuro lab for taking care of and providing the animals that were necessary to perform the experiments. We acknowledge and respect the $l \partial \mathrm{k}^{\mathrm{w}} \partial \mathrm{y}_{\partial \mathrm{n}}$ people on whose traditional territory the University of Victoria stands and the Songhees, Esquimalt and WSÁNEĆ peoples whose historical relationships with the land continue to this day.

de Oliveira, M. R., Nabavi, S. F., Nabavi, S. M., and Jardim, F. R. (2017). Omega-3 polyunsaturated fatty acids and mitochondria, back to the future. Trends Food Sci. Technol. 67, 76-92.

de Velasco, P. C., Mendonça, H. R., Borba, J. M. C., Andrade da Costa, B. L., da, S., Guedes, R. C. A., et al. (2012). Nutritional restriction of omega-3 fatty acids alters topographical fine tuning and leads to a delay in the critical period in the rodent visual system. Exp. Neurol. 234, 220-229. doi: 10.1016/j.expneurol.2011. 12.032

Decoeur, F., Benmamar-Badel, A., Leyrolle, Q., Persillet, M., Layé, S., and Nadjar, A. (2020). Dietary N-3 PUFA deficiency affects sleep-wake activity in basal condition and in response to an inflammatory challenge in mice. Brain. Behav. Immun. 85, 162-169. doi: 10.1016/j.bbi.2019.05.016

Del Rio-Hortega, P., and Penfield, W. (1932). Cytology \& [and] Cellular Pathology Of The Nervous System. New York, NY: Hoeber.

Delpech, J.-C., Madore, C., Joffre, C., Aubert, A., Kang, J. X., Nadjar, A., et al. (2015). Transgenic increase in $n-3 / n-6$ fatty acid ratio protects against cognitive deficits induced by an immune challenge through decrease of neuroinflammation. Neuropsychopharmacol. Off. Publ. Am. Coll. Neuropsychopharmacol. 40, 525-536. doi: 10.1038/npp.2014.196

El Hajj, H., Savage, J. C., Bisht, K., Parent, M., Vallières, L., Rivest, S., et al. (2019). Ultrastructural evidence of microglial heterogeneity in Alzheimer's disease amyloid pathology. J. Neuroinflammation 16:87. doi: 10.1186/s12974019-1473-9

Flachs, P., Horakova, O., Brauner, P., Rossmeisl, M., Pecina, P., Franssen-van Hal, N., et al. (2005). Polyunsaturated fatty acids of marine origin upregulate mitochondrial biogenesis and induce $\beta$-oxidation in white fat. Diabetologia 48 , 2365-2375. doi: 10.1007/s00125-005-1944-7

Fujita, Y., and Yamashita, T. (2021). Mechanisms and significance of microgliaaxon interactions in physiological and pathophysiological conditions. Cell. Mol. Life Sci. 78, 3907-3919. doi: 10.1007/s00018-021-03758-1

Gimeno-Bayón, J., López-López, A., Rodríguez, M. J., and Mahy, N. (2014). Glucose pathways adaptation supports acquisition of activated microglia phenotype. J. Neurosci. Res. 92, 723-731. doi: 10.1002/jnr.23356

Hagemeyer, N., Hanft, K.-M., Akriditou, M.-A., Unger, N., Park, E. S., Stanley, E. R., et al. (2017). Microglia contribute to normal myelinogenesis and to oligodendrocyte progenitor maintenance during adulthood. Acta Neuropathol. 134, 441-458. doi: 10.1007/s00401-017-1747-1

Han, J., Fan, Y., Zhou, K., Blomgren, K., and Harris, R. A. (2021). Uncovering sex differences of rodent microglia. J. Neuroinflammation 18:74. doi: 10.1186/ s12974-021-02124-z

Hellwig, S., Brioschi, S., Dieni, S., Frings, L., Masuch, A., Blank, T., et al. (2016). Altered microglia morphology and higher resilience to stress-induced depression-like behavior in CX3CR1-deficient mice. Brain. Behav. Immun. 55, 126-137. doi: 10.1016/j.bbi.2015.11.008

Hughes, A. N., and Appel, B. (2019). Developmental myelination is modified by microglial pruning. bioRxiv [Preprint].

Imamoto, K., and Leblond, C. P. (1978). Radioautographic investigation of gliogenesis in the corpus callosum of young rats. II. Origin of microglial cells. J. Comp. Neurol. 180, 139-163. doi: 10.1002/cne.901800109

Innis, S. M. (2007). Fatty acids and early human development. Early Hum. Dev. 83, 761-766. doi: 10.1016/j.earlhumdev.2007.09.004 
Isesele, P. O., and Mazurak, V. C. (2021). Regulation of skeletal muscle satellite cell differentiation by Omega-3 polyunsaturated fatty acids: a critical review. Front. Physiol. 12:682091. doi: 10.3389/fphys.2021.68209

Joffre, C., Grégoire, S., De Smedt, V., Acar, N., Bretillon, L., Nadjar, A., et al. (2016). Modulation of brain PUFA content in different experimental models of mice. Prostaglandins Leukot. Essent. Fatty Acids 114, 1-10. doi: 10.1016/j.plefa.2016. 09.003

Kalafatakis, I., and Karagogeos, D. (2021). Oligodendrocytes and microglia: key players in myelin development, damage and repair. Biomolecules 11:1058. doi: 10.3390/biom11071058

Kaur, C., Rathnasamy, G., and Ling, E.-A. (2017). Biology of microglia in the developing brain. J. Neuropathol. Exp. Neurol. 76, 736-753. doi: 10.1093/jnen/ nlx056

Kawakita, E., Hashimoto, M., and Shido, O. (2006). Docosahexaenoic acid promotes neurogenesis in vitro and in vivo. Neuroscience 139, 991-997. doi: 10.1016/j.neuroscience.2006.01.021

Koletzko, B., Lien, E., Agostoni, C., Böhles, H., Campoy, C., Cetin, I., et al. (2008). The roles of long-chain polyunsaturated fatty acids in pregnancy, lactation and infancy: review of current knowledge and consensus recommendations. J. Perinat. Med. 36, 5-14. doi: 10.1515/JPM.2008.001

$\mathrm{Ku}, \mathrm{R}$. Y., and Torii, M. (2020). New molecular players in the development of callosal projections. Cells 10:E29. doi: 10.3390/cells10010029

Labrousse, V. F., Leyrolle, Q., Amadieu, C., Aubert, A., Sere, A., Coutureau, E., et al. (2018). Dietary omega-3 deficiency exacerbates inflammation and reveals spatial memory deficits in mice exposed to lipopolysaccharide during gestation. Brain. Behav. Immun. 73, 427-440. doi: 10.1016/j.bbi.2018.06.004

Lafourcade, M., Larrieu, T., Mato, S., Duffaud, A., Sepers, M., Matias, I., et al. (2011). Nutritional omega-3 deficiency abolishes endocannabinoid-mediated neuronal functions. Nat. Neurosci. 14, 345-350. doi: 10.1038/nn.2736

Lampron, A., Larochelle, A., Laflamme, N., Préfontaine, P., Plante, M.-M., Sánchez, M. G., et al. (2015). Inefficient clearance of myelin debris by microglia impairs remyelinating processes. J. Exp. Med. 212, 481-495. doi: 10.1084/jem.20141656

Lands, W. E., Morris, A., and Libelt, B. (1990). Quantitative effects of dietary polyunsaturated fats on the composition of fatty acids in rat tissues. Lipids 25 , 505-516. doi: 10.1007/BF02537156

Lanza, I. R., Blachnio-Zabielska, A., Johnson, M. L., Schimke, J. M., Jakaitis, D. R., Lebrasseur, N. K., et al. (2013). Influence of fish oil on skeletal muscle mitochondrial energetics and lipid metabolites during high-fat diet. Am. J. Physiol. Endocrinol. Metab. 304, E1391-E1403. doi: 10.1152/ajpendo.00584. 2012

Lauritzen, L., Jørgensen, M. H., Olsen, S. F., Straarup, E. M., and Michaelsen, K. F. (2005). Maternal fish oil supplementation in lactation: effect on developmental outcome in breast-fed infants. Reprod. Nutr. Dev. 45, 535-547. doi: 10.1051/rnd: 2005044

Lauro, C., and Limatola, C. (2020). Metabolic reprograming of microglia in the regulation of the innate inflammatory response. Front. Immunol. 11:493. doi: 10.3389/fimmu.2020.00493

Lecours, C., St-Pierre, M.-K., Picard, K., Bordeleau, M., Bourque, M., Awogbindin, I. O., et al. (2020). Levodopa partially rescues microglial numerical, morphological, and phagolysosomal alterations in a monkey model of Parkinson's disease. Brain. Behav. Immun. 90, 81-96. doi: 10.1016/j.bbi.2020. 07.044

Lee, J., Hamanaka, G., Lo, E. H., and Arai, K. (2019). Heterogeneity of microglia and their differential roles in white matter pathology. CNS Neurosci. Ther. 25, 1290-1298. doi: 10.1111/cns.13266

Leyrolle, Q., Decoeur, F., Briere, G., Amadieu, C., Quadros, A. R. A. A., Voytyuk, I., et al. (2021a). Maternal dietary omega-3 deficiency worsens the deleterious effects of prenatal inflammation on the gut-brain axis in the offspring across lifetime. Neuropsychopharmacol. Off. Publ. Am. Coll. Neuropsychopharmacol. 46, 579-602. doi: 10.1038/s41386-020-00793-7

Leyrolle, Q., Decoeur, F., Dejean, C., Brière, G., Leon, S., Bakoyiannis, I., et al. (2021b). N-3 PUFA deficiency disrupts oligodendrocyte maturation and myelin integrity during brain development. Glia 70, 50-70. doi: 10.1002/glia.24088

Li, Q., Cheng, Z., Zhou, L., Darmanis, S., Neff, N. F., Okamoto, J., et al. (2019). Developmental heterogeneity of microglia and brain myeloid cells revealed by deep single-cell RNA sequencing. Neuron 101, 207.e-223.e. doi: 10.1016/j. neuron.2018.12.006
Ling, E. A. (1979). Transformation of monocytes into amoeboid microglia in the corpus callosum of postnatal rats, as shown by labelling monocytes by carbon particles. J. Anat. 128, 847-858.

Liu, P., Du, J.-L., and He, C. (2013). Developmental pruning of early-stage myelin segments during CNS myelination in vivo. Cell Res. 23, 962-964. doi: 10.1038/ cr.2013.62

Lloyd, A. F., and Miron, V. E. (2019). The pro-remyelination properties of microglia in the central nervous system. Nat. Rev. Neurol. 15, 447-458. doi: 10.1038/s41582-019-0184-2

Madore, C., Leyrolle, Q., Lacabanne, C., Benmamar-Badel, A., Joffre, C., Nadjar, A., et al. (2016). Neuroinflammation in autism: plausible role of maternal inflammation, dietary omega 3, and microbiota. Neural Plast. 2016:3597209. doi: 10.1155/2016/3597209

Madore, C., Leyrolle, Q., Morel, L., Rossitto, M., Greenhalgh, A. D., Delpech, J. C., et al. (2020). Essential omega-3 fatty acids tune microglial phagocytosis of synaptic elements in the mouse developing brain. Nat. Commun. 11:6133. doi: 10.1038/s41467-020-19861-z

Madore, C., Nadjar, A., Delpech, J.-C., Sere, A., Aubert, A., Portal, C., et al. (2014). Nutritional n-3 PUFAs deficiency during perinatal periods alters brain innate immune system and neuronal plasticity-associated genes. Brain. Behav. Immun. 41, 22-31. doi: 10.1016/j.bbi.2014.03.021

Martinat, M., Rossitto, M., Di Miceli, M., and Layé, S. (2021). Perinatal dietary polyunsaturated fatty acids in brain development. Role in neurodevelopmental disorders. Nutrients 13:1185. doi: 10.3390/nu13041185

McNamara, N. B., and Miron, V. E. (2020). Microglia in developing white matter and perinatal brain injury. Neurosci. Lett. 714:134539. doi: 10.1016/j.neulet. 2019.134539

McNamara, R. K., Szeszko, P. R., Smesny, S., Ikuta, T., DeRosse, P., Vaz, F. M., et al. (2017). Polyunsaturated fatty acid biostatus, phospholipase A2 activity and brain white matter microstructure across adolescence. Neuroscience 343 , 423-433. doi: 10.1016/j.neuroscience.2016.12.007

McNamara, R. K., Vannest, J. J., and Valentine, C. J. (2015). Role of perinatal long-chain omega-3 fatty acids in cortical circuit maturation: mechanisms and implications for psychopathology. World J. Psychiatry 5, 15-34. doi: 10.5498/ wjp.v5.i1.15

Milior, G., Lecours, C., Samson, L., Bisht, K., Poggini, S., Pagani, F., et al. (2016). Fractalkine receptor deficiency impairs microglial and neuronal responsiveness to chronic stress. Brain. Behav. Immun. 55, 114-125. doi: 10.1016/j.bbi.2015.07. 024

Miron, V. E., Boyd, A., Zhao, J.-W., Yuen, T. J., Ruckh, J. M., Shadrach, J. L., et al. (2013). M2 microglia/macrophages drive oligodendrocyte differentiation during CNS remyelination. Nat. Neurosci. 16, 1211-1218. doi: 10.1038/nn.3469

Nadjar, A. (2018). Role of metabolic programming in the modulation of microglia phagocytosis by lipids. Prostaglandins Leukot. Essent. Fatty Acids 135, 63-73. doi: 10.1016/j.plefa.2018.07.006

Nahirney, P. C., and Tremblay, M.-E. (2021). Brain ultrastructure: putting the pieces together. Front. Cell Dev. Biol. 9:187. doi: 10.3389/fcell.2021.629503

Nemes-Baran, A. D., White, D. R., and DeSilva, T. M. (2020). Fractalkinedependent microglial pruning of viable oligodendrocyte progenitor cells regulates myelination. Cell Rep. 32:108047. doi: 10.1016/j.celrep.2020.108047

O'Neill, L. A. J., Kishton, R. J., and Rathmell, J. (2016). A guide to immunometabolism for immunologists. Nat. Rev. Immunol. 16, 553-565. doi: 10.1038/nri.2016.70

Orihuela, R., McPherson, C. A., and Harry, G. J. (2016). Microglial M1/M2 polarization and metabolic states. Br. J. Pharmacol. 173, 649-665. doi: 10.1111/ bph.13139

Pang, Y., Fan, L.-W., Tien, L.-T., Dai, X., Zheng, B., Cai, Z., et al. (2013). Differential roles of astrocyte and microglia in supporting oligodendrocyte development and myelination in vitro. Brain Behav. 3, 503-514. doi: 10.1002/brb3.152

Paolicelli, R. C., and Angiari, S. (2019). Microglia immunometabolism: from metabolic disorders to single cell metabolism. Semin. Cell Dev. Biol. 94, 129137. doi: $10.1016 /$ j.semcdb.2019.03.012

Park, H.-J., Kim, J. J., Lee, S.-K., Seok, J. H., Chun, J., Kim, D. I., et al. (2008). Corpus callosal connection mapping using cortical gray matter parcellation and DT-MRI. Hum. Brain Mapp. 29, 503-516. doi: 10.1002/hbm.20314

Pasquini, L. A., Millet, V., Hoyos, H. C., Giannoni, J. P., Croci, D. O., Marder, M., et al. (2011). Galectin-3 drives oligodendrocyte differentiation to control myelin 
integrity and function. Cell Death Differ. 18, 1746-1756. doi: 10.1038/cdd.20 11.40

Pifferi, F., Roux, F., Langelier, B., Alessandri, J.-M., Vancassel, S., Jouin, M., et al. (2005). (n-3) Polyunsaturated fatty acid deficiency reduces the expression of both isoforms of the brain glucose transporter GLUT1 in rats. J. Nutr. 135, 2241-2246. doi: 10.1093/jn/135.9.2241

Putnam, M. C., Steven, M. S., Doron, K. W., Riggall, A. C., and Gazzaniga, M. S. (2010). Cortical projection topography of the human splenium: hemispheric asymmetry and individual differences. J. Cogn. Neurosci. 22, 1662-1669. doi: 10.1162/jocn.2009.21290

Rapoport, S. I., Rao, J. S., and Igarashi, M. (2007). Brain metabolism of nutritionally essential polyunsaturated fatty acids depends on both the diet and the liver. Prostaglandins Leukot. Essent. Fatty Acids 77, 251-261. doi: 10.1016/j.plefa. 2007.10.023

Rohrbach, S. (2009). Effects of dietary polyunsaturated fatty acids on mitochondria. Curr. Pharm. Des. 15, 4103-4116. doi: 10.2174/138161209789909692

Sastry, P. S. (1985). Lipids of nervous tissue: composition and metabolism. Prog. Lipid Res. 24, 169-176. doi: 10.1016/0163-7827(85)90011-6

Savage, J. C., St-Pierre, M.-K., Carrier, M., El Hajj, H., Novak, S. W., Sanchez, M. G., et al. (2020). Microglial physiological properties and interactions with synapses are altered at presymptomatic stages in a mouse model of Huntington's disease pathology. J. Neuroinflammation 17:98. doi: 10.1186/s12974-020-01782-9

Shigemoto-Mogami, Y., Hoshikawa, K., Goldman, J. E., Sekino, Y., and Sato, K. (2014). Microglia enhance neurogenesis and oligodendrogenesis in the early postnatal subventricular zone. J. Neurosci. Off. J. Soc. Neurosci. 34, 2231-2243. doi: 10.1523/JNEUROSCI.1619-13.2014

Shu, S. Y., Ju, G., and Fan, L. Z. (1988). The glucose oxidase-DAB-nickel method in peroxidase histochemistry of the nervous system. Neurosci. Lett. 85, 169-171. doi: 10.1016/0304-3940(88)90346-1

Sierra, A., Paolicelli, R. C., and Kettenmann, H. (2019). Cien años de microglía: milestones in a century of microglial research. Trends Neurosci. 42, 778-792.

Stark, K. D., Van Elswyk, M. E., Higgins, M. R., Weatherford, C. A., and Salem, N. (2016). Global survey of the omega-3 fatty acids, docosahexaenoic acid and eicosapentaenoic acid in the blood stream of healthy adults. Prog. Lipid Res. 63, 132-152. doi: 10.1016/j.plipres.2016.05.001

St-Pierre, M.-K., Bordeleau, M., and Tremblay, M. -È (2019). "Visualizing dark microglia," in Microglia: Methods and Protocols, eds O. Garaschuk and A. Verkhratsky (New York, NY: Springer), 97-110.

Stratoulias, V., Venero, J. L., Tremblay, M., and Joseph, B. (2019). Microglial subtypes: diversity within the microglial community. EMBO J. 38:e101997. doi: 10.15252/embj.2019101997

Su, W.-J., Zhang, T., Jiang, C.-L., and Wang, W. (2018). Clemastine alleviates depressive-like behavior through reversing the imbalance of microglia-related pro-inflammatory state in mouse hippocampus. Front. Cell. Neurosci. 12:412. doi: 10.3389/fncel.2018.00412
Tanabe, S., and Yamashita, T. (2020). Function of lymphocytes in oligodendrocyte development. Neuroscientist 26, 74-86. doi: 10.1177/1073858419834221

Traiffort, E., Kassoussi, A., Zahaf, A., and Laouarem, Y. (2020). Astrocytes and microglia as major players of myelin production in normal and pathological conditions. Front. Cell. Neurosci. 14:79. doi: 10.3389/fncel.2020.00079

Tremblay, M. -È, Lowery, R. L., and Majewska, A. K. (2010). Microglial interactions with synapses are modulated by visual experience. PLoS Biol. 8:e1000527. doi: 10.1371/journal.pbio.1000527

Wahl, M., Lauterbach-Soon, B., Hattingen, E., Jung, P., Singer, O., Volz, S., et al. (2007). Human motor corpus callosum: topography. somatotopy, and link between microstructure and function. J. Neurosci. 27, 12132-12138. doi: 10. 1523/JNEUROSCI.2320-07.2007

Wlodarczyk, A., Holtman, I. R., Krueger, M., Yogev, N., Bruttger, J., Khorooshi, R., et al. (2017). A novel microglial subset plays a key role in myelinogenesis in developing brain. EMBO J. 36, 3292-3308. doi: 10.15252/embj.20169 6056

Xie, D., Ge, X., Ma, Y., Tang, J., Wang, Y., Zhu, Y., et al. (2020). Clemastine improves hypomyelination in rats with hypoxic-ischemic brain injury by reducing microglia-derived IL-1 $\beta$ via P38 signaling pathway. J. Neuroinflammation 17:57. doi: 10.1186/s12974-019-16 62-6

Yavin, E., Himovichi, E., and Eilam, R. (2009). Delayed cell migration in the developing rat brain following maternal omega 3 alpha linolenic acid dietary deficiency. Neuroscience 162, 1011-1022. doi: 10.1016/j.neuroscience.2009.05. 012

Zareba, J., and Peri, F. (2021). Microglial 'fat shaming' in development and disease. Curr. Opin. Cell Biol. 73, 105-109. doi: 10.1016/j.ceb.2021.07.007

Conflict of Interest: The authors declare that the research was conducted in the absence of any commercial or financial relationships that could be construed as a potential conflict of interest.

Publisher's Note: All claims expressed in this article are solely those of the authors and do not necessarily represent those of their affiliated organizations, or those of the publisher, the editors and the reviewers. Any product that may be evaluated in this article, or claim that may be made by its manufacturer, is not guaranteed or endorsed by the publisher.

Copyright (c) 2022 Decoeur, Picard, St-Pierre, Greenhalgh, Delpech, Sere, Layé, Tremblay and Nadjar. This is an open-access article distributed under the terms of the Creative Commons Attribution License (CC BY). The use, distribution or reproduction in other forums is permitted, provided the original author(s) and the copyright owner(s) are credited and that the original publication in this journal is cited, in accordance with accepted academic practice. No use, distribution or reproduction is permitted which does not comply with these terms. 